\title{
The role of hunger in schedule-induced polydipsia
}

\author{
VIRGINIA BRUCE-WOLFE, WILLIAM J. FREED, and JOSEPH MENDELSON \\ University of Kansas, Lawrence, Kansas 66045
}

\begin{abstract}
Food-satiated rats bearing feeding-inducing hypothalamic electrodes were given one 45-mg food pellet per minute during 60-min daily sessions, with water continuously available. Electrical stimulation of the lateral hypothalamus (ESLH) was turned on for 3 or $15 \mathrm{sec}$, either concurrently with pellet delivery or $2-4 \mathrm{sec}$ thereafter. Fifteen seconds of ESLH generated schedule-induced polydipsia (SIP), but $3 \mathrm{sec}$ did not. When $15 \mathrm{sec}$ of ESLH was delayed for $4 \mathrm{sec}$, strong SIP was manifested even though each ESLH was only initiated after each pellet had been consumed. It is concluded that postpellet hunger is necessary to produce SIP. Hunger during pellet consumption is neither a necessary nor a sufficient condition.
\end{abstract}

When a rat that has been food deprived is intermittenly fed small amounts of food (e.g., one 45-mg Noyes pellet every minute) it gradually develops a tendency to drink water immediately after consuming each morsel of food (Falk, 1971, reviews these studies). Under optimal parameters a rat will drink up to one-half to two-thirds of its body weight during a 3.5 -h session (Falk, 1969). This water is consumed although the rat has no apparent physiological need for it; in fact, drinking continues unabated even after it has led to overhydration of the rat's blood plasma and muscle tissue (Stricker \& Adair, 1966).

One of the important parameters controlling the intensity of this "schedule-induced polydipsia" (SIP) is the hunger ${ }^{1}$ level of the rat (Falk, 1971). The stronger the hunger (e.g., the greater the body-weight loss engendered by food deprivation), the greater the degree of polydipsia. The present experiment was designed to determine the precise role of hunger in the induction of SIP. Specifically, is the occurrence or intensity of SIP a function of the hunger level present while the pellet is being consumed, the hunger level present during the interpellet interval (IPI), or both? Falk (1971) suggests that "it seems reasonable to suppose that interfering with strong feeding responses would induce stronger adjunctive behavior than interfering with weak feeding responses" (p. 580; Falk considers SIP to be a form of "adjunctive behavior"). If this is correct, and if the "strength of the feeding response" increases with hunger, then it is the hunger level during pellet consumption which influences the occurrence or intensity of SIP.

On the other hand, Falk (1971) relates SIP to the "displacement activities" described by ethologists. Displacement activities typically occur in situations in which a consummatory behavior, or the "drive" to engage in a consummatory behavior, is thwarted.

Supported in part by grants to V. B. -W. (dissertation fellowship from the University of Kansas) and to J. M. (Grant 30805038 from the University of Kansas General Research Fund). Data reported in this paper were presented by the senior author at the Fifth Annual Meeting of the Society of Neuroscience, New York, New York, 1975.
Accordingly, SIP might develop as a response to the thwarting or frustration of hunger-induced feeding, which is brought about by the termination of food availability each time the rat finishes a pellet. This view would suggest that it is the level of IPI hunger, whose feeding tendencies are frustrated, which determines the intensity of SIP. If hunger was terminated just after each pellet was consumed, then according to this view, SIP would fail to develop.

In order to determine the exact role of hunger in generating SIP, it is necessary to use a form of hunger which can be turned on and off almost instantaneously (Mendelson, 1966). Electrical stimulation of the lateral hypothalamus (ESLH) induces a feeding tendency which in many respects resembles deprivation-induced hunger (Wise, 1974). In the present experiment, food- and water-satiated rats bearing feeding-inducing electrodes in the lateral hypothalamus were given 1-h daily sessions during which one $45-\mathrm{mg}$ food pellet was delivered each minute. Each animal was tested under at least two conditions: (1) simultaneously with pellet delivery, a 3-sec period of ESLH was initiated, and (2) the 3-sec ESLH was lengthened to $15 \mathrm{sec}$ and followed by a second 15 sec of ESLH delivered during the third quarter of the IPI. The purpose of this second period of stimulation was to attempt to dissociate SIP from stimulus-bound (S-B) drinking. Since SIP drinking immediately follows pellet consumption (providing that water is continuously available during the entire IPI), any drinking that would occur during the second 15-sec period of ESLH would most likely be stimulus bound rather than schedule induced. Thus, if this second stimulation period was not employed, one would not know whether any drinking which might occur during the first 15 -sec ESLH was a manifestation of SIP or S-B drinking.

\section{METHOD}

\section{Subjects}

The subjects were eight naive hooded female rats weighing $250-350 \mathrm{~g}$ at the start of the experiment. Of 40 rats in which electrodes had been implanted, these eight animals were the only 
ones in which ESLH reliably elicited S-B feeding, but not S-B drinking, in the satiated state.

\begin{abstract}
Apparatus
The rats were tested for SIP in a covered Plexiglas cylinder, $25 \mathrm{~cm}$ in diam and $42 \mathrm{~cm}$ high, mounted on a wire mesh floor. A foodcup was positioned on the floor against one side of the cylinder. On the opposite side, a drinking tube protruded into the cylinder through a hole $6 \mathrm{~cm}$ above the floor. Noyes food pellets $(45-\mathrm{mg})$ could be automatically delivered in the foodcup by means of a Davis pellet dispenser. Contacts with the drinking tube were detected by a Grason-Stadler drinkometer and recorded on running time meters and an event recorder. Electromechanical equipment was used to program schedules of ESLH and food-pellet delivery. ESLH consisted of $60-\mathrm{Hz}$ sine-wave current delivered from a constant-current stimulator.
\end{abstract}

\section{Procedure}

Surgery and screening. Each rat was bilaterally implanted with two bipolar electrodes, one aimed at each lateral hypothalamus, according to a procedure described elsewhere (Mendelson, 1970). At least 1 week after surgery, each electrode was screened for S-B eating by applying ESLH at 0-35 microampere. This testing was conducted in a Plexiglas cylinder of the same dimensions as the SIP chamber, with six equally spaced drinking tubes protruding from holes in the wall, located $6 \mathrm{~cm}$ above the floor. A number of Purina Lab Chow food pellets were scattered over the floor. If an animal did not eat in response to ESLH, the food pellets were replaced with a full dish of fresh mash and testing was continued.

Protection against emergence of S-B drinking. In preliminary experiments $^{2}$ we discovered that one of the major obstacles to running this experiment in a theoretically meaningful way was that S-B feeders tended to rapidly acquire a tendency to add drinking to their S-B repertoire. Consequently, for such animals it would be impossible to dissociate S-B drinking from SIP. Fortunately, in the interim since those experiments were run, Valenstein (1971) discovered that extensive ESLH experience with only food available can greatly decrease the likelihood that S-B feeders will later develop S-B drinking. Accordingly, before running the SIP tests, we attempted to protect our animals against the emergence of S-B drinking by submitting them to 30 ESLH tests with only food available. Each test consisted of 30 20-sec stimulations, with a 40-sec interstimulation interval.

SIP training under food deprivation. The subjects were then reduced to $80 \%$ of their ad-lib body weights by restricting their food intake. Each rat, upon reaching this weight level, was subjected to a series of $1-\mathrm{h}$ daily SIP tests during which a food pellet was automatically delivered each minute. No ESLH was given. This SIP training was continued for 10 sessions, or until each animal exhibited drinking on $90 \%$ of its IPIs, whichever came first.

Testing for post-ESLH inhibition of drinking. Since there is evidence for post-ESLH inhibition of consummatory behavior in some rats (Cox et al., 1969), we also tested our food-deprived rats under the previous condition, with the addition of a 3-sec period of ESLH initiated simultaneously with each pellet delivery. (Three seconds was the average amount of time required to consume each pellet.) Each animal was given two 1-h sessions, with the 3-sec periods of ESLH applied only during the first half of the first session and during the second half of the second session.

SIP testing with 3-sec ESLH. The rats were returned to their ad-lib body weights and given four daily 1-h SIP sessions, with 3 -sec periods of ESLH delivered as above. One hour before each session, a foodcup containing over $20045-\mathrm{mg}$ Noyes pellets was placed in each rat's home cage in order to presatiate it on the test food. No animal ever finished all these pellets.

SIP testing with 15-sec ESLH. Four sessions were given under testing conditions identical to those just described except that
(1) the 3-sec periods of ESLH were extended to $15 \mathrm{sec}$ and (2) a second 15-sec period of ESLH was delivered during the third quarter of each IPI.

Delay condition. The animals which did not become S-B drinkers during the 15 -sec condition were tested for SIP, with $15 \mathrm{sec}$ of ESLH initiated 2 or $4 \mathrm{sec}$ after each pellet delivery. One session with each delay was given to each rat.

Histology. At the end of the experiment, the rats were perfused with $10 \%$ formalin, and their brains removed and sectioned at 50 microns. Photographs of the sections were obtained by projecting their images directly onto photographic paper.

\section{RESULTS}

By the 10th session of SIP training under food deprivation, each rat was drinking on at least $90 \%$ of its IPIs. During the last four sessions of preliminary training, the rats drank on a mean of $84 \%$ of the IPIs. At this point, Rat $3 \mathrm{~L}$ pulled out its electrodes and was dropped from the experiment. During testing for postESLH inhibition, the remaining seven rats drank on a mean of $82 \%$ of the IPIs during the half sessions, when $3 \mathrm{sec}$ of ESLH was initiated concurrently with pellet delivery. This was only $1 \%$ lower than the drinking scores obtained on the control half sessions, during which no ESLH was administered.

When the animals were returned to their free-feeding weights and tested with 3-sec periods of ESLH, drinking occurred on only $16 \%$ of the IPIs. In contrast, during the 15 -sec condition all of the rats usually drank during the first 15-sec ESLH of each IPI. However, four of the seven rats also drank during the second 15 -sec periods of ESLH which were not temporally associated with eating; evidently they had developed S-B drinking.

Figure 1 compares the drinking behavior of the animals which only engaged in S-B feeding with that of the animals which engaged in both S-B feeding and drinking. It can be seen that during the last two sessions of the 15-sec condition, SIP for the S-B feeders was comparable to that which occurred during the last four sessions of preliminary training. Typically, the rats in this group grasped the pellet as soon as it was delivered, consumed it, and then drank until ESLH ceased. The S-B feeders and drinkers often did not eat in response to pellet delivery, but instead began to drink as soon as the ESLH was turned on.

During the 2- and 4-sec delay conditions, drinking continued to occur for means of $93 \%$ and $82 \%$ of the IPIs. Although the rats were presatiated with the test food prior to each experimental session, they ate each pellet as soon as it was delivered. They did not wait for the ESLH to go on before beginning to eat; in fact, during the 4-sec delay condition they always finished eating before the ESLH began.

\section{Histology}

All the electrodes were found to lie in or around the lateral hypothalamic area at points which have previously been shown to yield S-B feeding and drinking. 


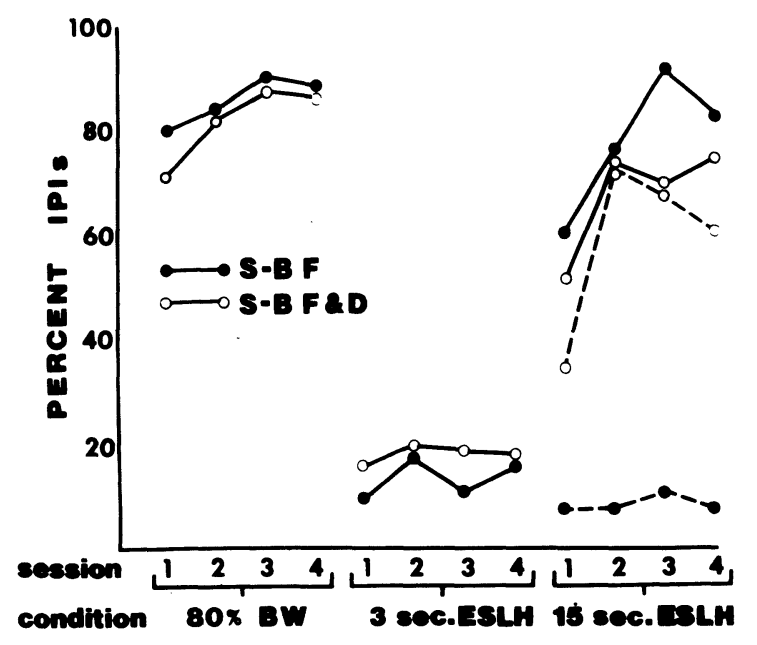

Figure 1. The mean percentage of IPIs on which S-B eaters (filled circles) and S-B feeders and drinkers (unfilled circles) drank immediately after pellet delivery during the last four sessions of preliminary training and all the nondelay sessions run under the 3- and 15-sec conditions. The dotted line represents drinking during the third quarter of the IPI, when a second 15 sec period of ESLH was delivered.

\section{DISCUSSION}

The results of the present experiment indicate that (1) hunger during pellet consumption is neither a necessary nor a sufficient condition for the induction of SIP, and (2) hunger during the IPI is a necessary condition for SIP. Before these results were obtained, it was possible to argue that the effect of hunger level on SIP was mediated by the strength of the feeding response or by the interaction between hunger and the reinforcing value of food. Thus, one could have maintained that the reason why mild hunger fails to sustain SIP (Falk, 1971) is because of the weakness of the feeding response or the low potency of the food reinforcer for a rat that is only mildly hungry, and that intermittent brief episodes of strong feeding or strong positive reinforcement are sufficient to generate SIP. However, the results of our 3-sec condition rule out any such interpretation. Although the 3 -sec stimulations presumably increased the strength of the feeding responses and the reinforcement value of the pellets (Coons \& Cruce, 1968), they failed to induce SIP. Thus, SIP was not engendered by the interruption of the strong feeding response that was presumably elicited by the 3-sec stimulations accompanying pellet consumption. On the other hand, if the ESLH was allowed to continue even after the consumption of each pellet had been completed, strong SIP emerged. Furthermore, during the delay condition, strong SIP occurred even though the ESLH was not turned on until after each pellet had been consumed under what had presumably been very weak hunger. The present data do not support the displacement hypothesis of SIP, nor do they support the suggestion that interruption of a strong feeding response generates stronger SIP than interruption of a weak feeding response. We conclude that when food pellets are consumed according to a schedule such as that employed in the present experiment, the termination of feeding sets up a central state which, in conjunction with hunger, will elicit strong drinking behavior.

\section{NOTES}

1. Throughout this paper, the term "hunger" is employed to refer to a central state under which there is a high probability that available food will be consumed, whether this state is brought about by food deprivation or by electrical stimulation of the lateral hypothalamus. It is an open question whether the conclusions of this paper with respect to the latter form of hunger can be extended to the former.

2. These experiments were conducted by Joseph Mendelson, Joe Berman, Daniel Sobel, and Ira L. Cohen at the University of Michigan and McGill University in 1967 and at Rutgers University in 1969, supported by grants to Joseph Mendelson, Stephen E. Glickman, James Olds, and Dalbir Bindra.

\section{REFERENCES}

Coons, E. E., \& Cruce, J. A. F. Lateral hypothalamus: Food and current intensity in maintaining self-stimulation of hunger. Science, 1968, 159, 1117-1119.

Cox, V. C., Kakolewski, J. W., \& Valenstein, E. S. Inhibition of eating and drinking following hypothalamic stimulation. Journal of Comparative and Physiological Psychology, 1969, 68, 530-535.

FALK, J. L. Conditions producing psychogenic polydipsia in animals. Annals of the New York Academy of Sciences, 1969, 157, 569-589.

FALK, J. L. The nature and determinants of adjunctive behavior. Physiology and Behavior, 1971, 6, 577-588.

Mendelson, J. The role of hunger in T-maze learning for food by rats. Journal of Comparative and Physiological Psychology, 1966, 62, 341-349.

Mendelson, J. Self-induced drinking in rats: The qualitative identity of drive and reward systems in the lateral hypothalamus. Physiology and Behavior, 1970, 5, 925-930.

Stricker, E. M., \& Adair, E. R. Body fluid balance, taste, and postprandial factors in schedule-induced polydipsia. Journal of Comparative and Physiologieal Psychology, 1966, 62, 449-454.

Valenstein, E. S. Channeling of responses elicited by hypothalamic stimulation. Journal of Psychiatric Research, 1971, 8, 335-344.

WISE, R. A. Lateral hypothalamic electrical stimulation: Does it make animals hungry? Brain Research, 1974, 67, 187-209. 